May also saw the formal introduction of the Patient-Centered Primary Care Collaborative. Members of the collaborative-which include the AAFP and other physician groups, health care organizations, and employers - agreed that placing primary care and the patient-centered medical home "center stage" in the health care debate would help put America's ailing health care system back on the road to recovery.

Late in May, some of the nation's largest professional health care organizations, including the AAFP, sent a proposal to Congress asking lawmakers to phase in a repeal of Medicare's sustainable growth rate, or SGR, formula by 2016 if they could not immediately eliminate the program. According to (then) AAFP Board Chair Larry Fields, MD, of Flatwoods, Kentucky, Congress needs to create a "stable payment system" for the next few years while working on a "permanent fix for the broken system we have now."

The Academy's efforts for payment reform continued in July, when Kellerman and other primary care leaders sat down with congressional leaders and asked them to stop the scheduled $10 \%$ reduction in Medicare payment rates for 2008 and provide positive payment updates in 2008 and 2009. "Everyone agrees this formula does not work," said Kellerman.

For a while in August, it looked as if fixing the payment cuts called for by the SGR would not have to wait until the end of the year when the House passed a bill that would provide slight increases in Medicare physician payments in 2008 and 2009. The provision, which was passed as part of a bill to reauthorize the State Children's Health Insurance Program, or SCHIP, would have provided a $0.5 \%$ increase in physician payments in both 2008 and 2009. Unfortunately, the payment update did not survive the reconciliation process between the House and the Senate.

With the collapse of the House SCHIP bill, the Academy intensified its advocacy efforts to stop Medicare payment cuts. In September, Kellerman met with staff members in the offices of 3 senators on the Senate Finance Committee and urged them to support a 2year physician payment increase. "There is a growing understanding that primary care physicians and family physicians in particular are being undervalued in the current system, and that is having an adverse effect on access and quality of care and medical student specialty choice," said Kellerman.

In October, the Academy unveiled a new attitude about advocacy with its "Bold Champions" initiative. The 2-year, multimillion-dollar strategic initiative is designed to represent members with assertive actions, forceful language, and a new brand identity to telegraph the change in its approach. "This new campaign expresses the AAFP's commitment to play a central role in reforming the health care system for the benefit of all," said newly installed AAFP President Jim King, MD, of Selmer, Tennessee.

The threat to legislation seeking to alleviate the scheduled payment cut spurred the Academy to mobilize its members in November and December. The AAFP urged members to call their senators to stop the pending cuts, and members responded by bombarding Capitol Hill with phone calls saying that Medicare pay cuts were unacceptable. These efforts were rewarded somewhat in the waning hours of December, when the Senate and House passed legislation that provided for a $0.5 \%$ increase for the first 6 months of 2008 . However, it was a poor attempt at a fix in the Academy's eyes. Congress is engaged in a delaying action, said King, postponing "what needs to happen, which is a complete reevaluation of the payment system and an elimination of the SGR in order to bring some sanity to our present payment formula."

The new year dawned with the Academy working hard to once again mobilize members to call Congress' attention to the Medicare payment crisis. While the Senate Finance Committee and members of the House quickly turned their attention to finding a way to fix or extend the temporary increase, AAFP members worked on a campaign to ensure the Medicare issue remained front and center.

Although the outcome of members' efforts is still unknown, the Academy has succeeded in bringing the critical issue of payment reform to the attention of key legislators, as well as presidential candidates, with the hope that the patient-centered primary care medical home soon will become the model for health care across the nation.

AAFP News Now Staff

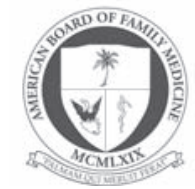

From the American

Board of Family Medicine

Ann Fam Med 2008;6:183-184. DOI: 10.1370/afm.825.

\section{A NEW FOCUS ON RESEARCH}

Self-assessment is an ongoing and increasingly extensive process. As a matter of basic ethics and good conscience, the ABFM cannot require diplomates to scrutinize their knowledge and practices if we are not equally willing to engage in a perpetual and data driven self-evaluation. As such, a vector of the ABFM's research direction will be self-reflective. We will evaluate the effects of changes instituted since ABFM began 
the Maintenance of Certification processes in 2004 and the validity of our assessment processes. There are many questions that we have addressed already, but there are far more that have yet to be addressed. For example, we have been gathering data from participants in the Maintenance of Certification program regarding their impressions of the MC-FP process. Feedback has been markedly positive. After completing a single Self-Assessment Module (SAM), one-half of all respondents indicated that they will change their practice as a result of their participation. More than $90 \%$ of these physicians listed 1 or more specific behaviors that they intend to alter based on material presented in the SAM process. Although this data appears positive, we do not assume that the data are either static or definitive.

Another key initiative for research is the promotion of research within family medicine. This will be accomplished, in part, by making de-identified data available to family medicine affiliated organizations, for research purposes related to family medicine. To that end, we are encouraging submission of data and research requests for review. Historically, the ABFM has supported research of this type on an ad hoc basis, as inquiries about data availability arise. However, we now seek sources for productive research collaboration on both a long-term and short-term basis. Some examples of requests that we have had in the past sev- eral years include whether exam scores were affected positively or negatively by changes to work hours rules and whether the presence of affiliated Sports Medicine fellowship programs affect performance on Sports Medicine-related certification exam questions. The ABFM would like to thank those who have submitted research support requests. The breadth of inquiries is a testament to the diversity of intellectual interests across our specialty. There remain a multitude of relevant and interesting questions to be asked by creative family medicine researchers.

One of our large ongoing projects is a practice efficiency study with the American Board of Internal Medicine (ABIM) and the Dartmouth Primary Care Study Group. Another project that is similar in scope is working to identify contributing factors and multiyear trends of performance differences based on the location of medical training (United States, Canada, other international locations). This issue arose initially after a report showing that Canadian-trained physicians performed persistently highly upon examination compared to the overall group of candidates. If training differences or other factors can be identified that appear to confer a higher level of medical knowledge, then their dissemination potentially could be of widespread benefit.

Jason C.B. Rinaldo, $\mathrm{PbD}$ 